\title{
Pneumologia
}

\section{The second SRP-SRAIC conference - another face of asthma disease}

Florin Mihălțan*

\section{A II-a Conferință Interdisciplinară Alergologie \& Pneumologie}

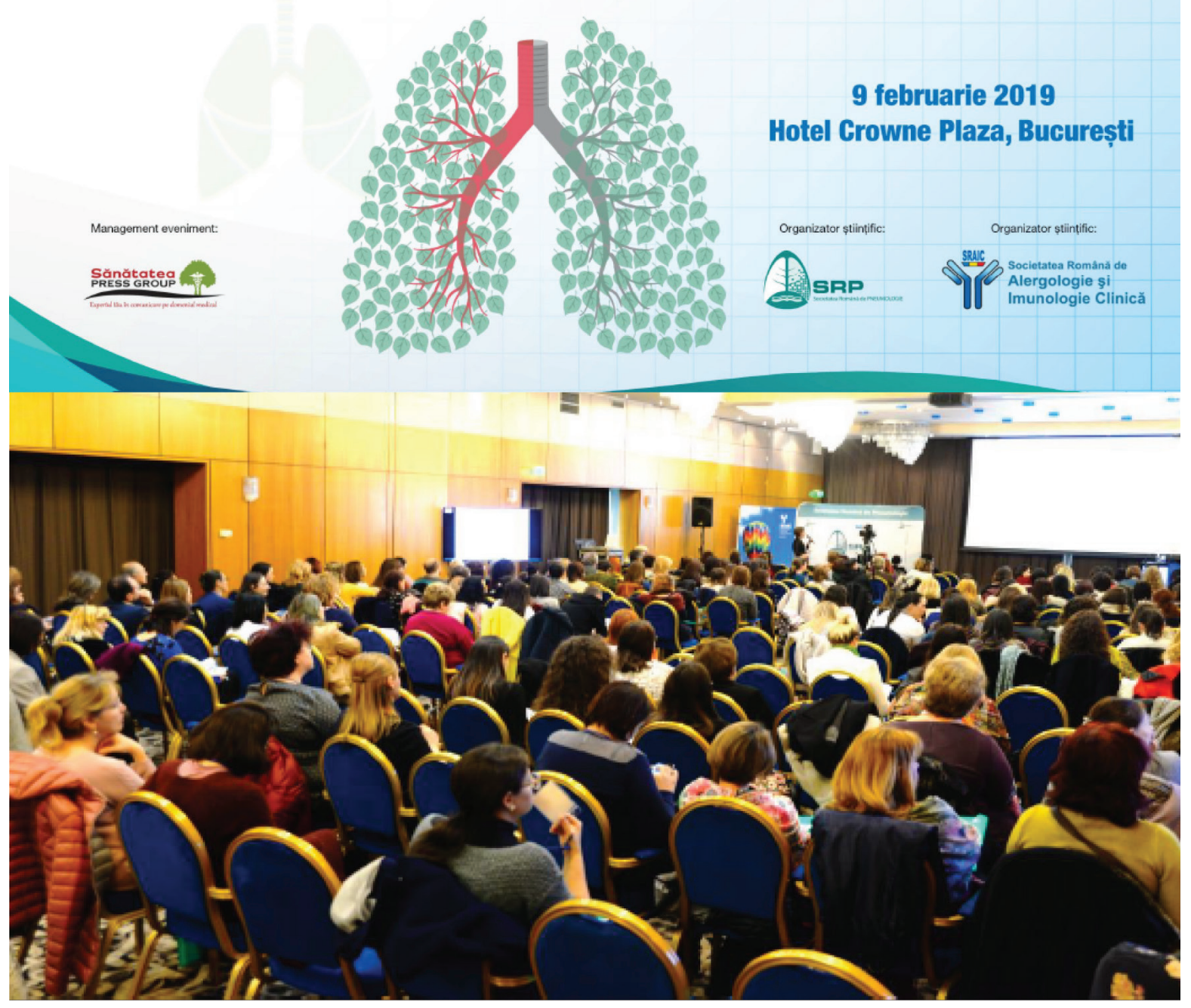

*Corresponding author: Florin Mihălțan E-mail:mihaltan@starnets.ro 


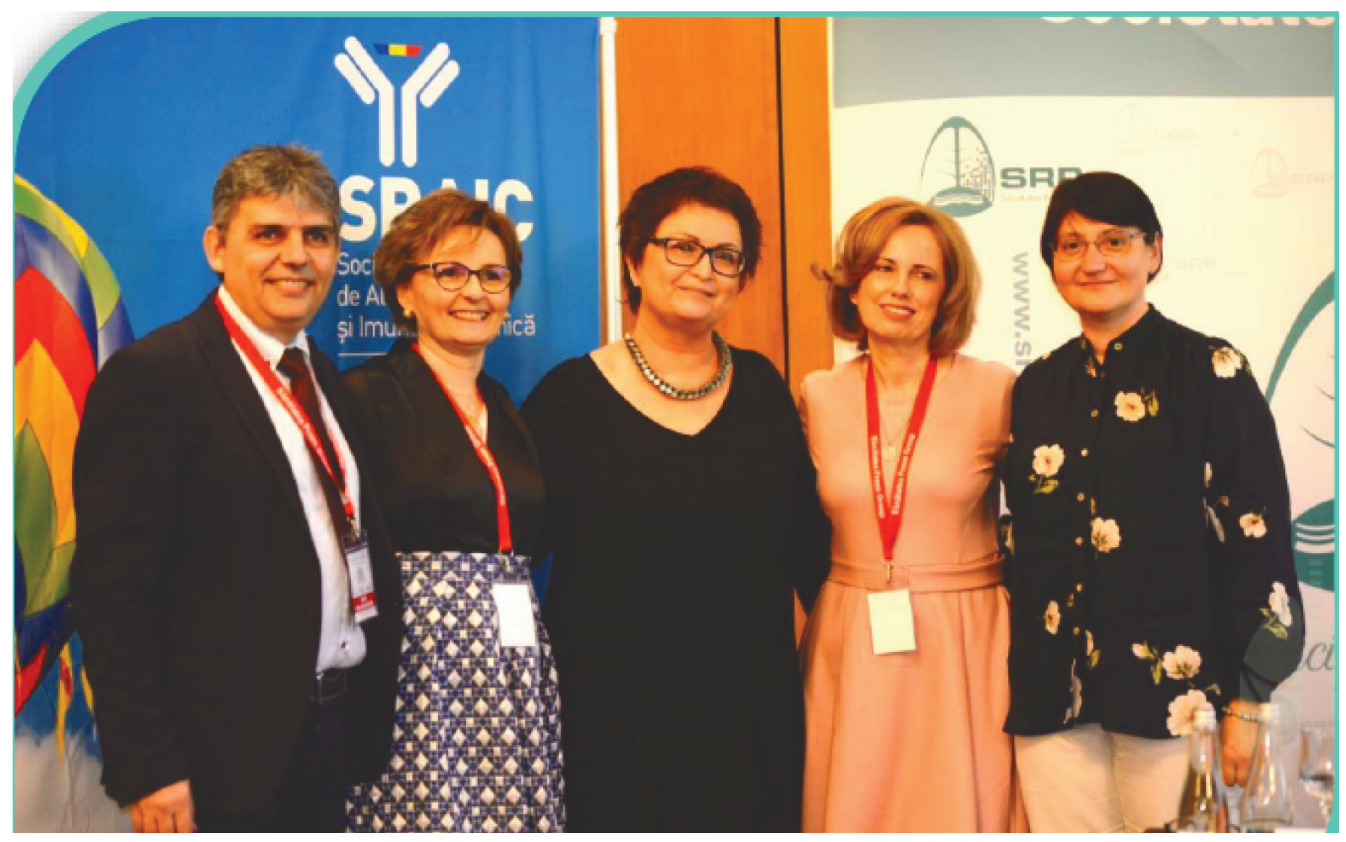

February started to be traditionally reserved for the joint conference of the Romanian Pneumology Society (SRP) and the Romanian Society of Allergy and Clinical Immunology (SRAIC). 9 February 2019 marked the second conference of these two societies with quality scientific offers and new topics that are rarely addressed in the Romanian medical world. Twelve colleagues contributed to the good running of the conference who have chosen topics on the border between several specialities.

The morning session included presentations, such as "Asthma and the diet" (Florin Mihălțan and Anca Hâncu) with a detailed analysis of the interferences between the asthmatic condition and the new lifestyle where the diet should acquire another value, "Asthma associated with storms with electric discharges" (Florin-Dan Popescu) which revealed the increasingly important link between climate change and asthma attacks, "Asthma management in pregnancy" (Dragoș Bumbăcea) with a clarification of the aspects related to the clinic and therapy during the pregnancy and "Biological pollution and air quality from the perspective of the allergist" (Poliana Leru) who outlined the aggressive modalities of the intervention of the polluting factors in the world of allergies and the prevention methods applicable under these conditions.

The second session was equally interesting. Here in turn, the reviewed topics were "Allergological evaluation in severe asthma" (Roxana Bumbăcea) which analyzed the modalities to assess severe forms of asthma, "Types of biological therapy in asthma" (Claudia Toma) with a clarification of the usefulness and precautions imposed by this form of therapy with biological agents, "Lung in the context of hypereosinophilic syndromes" (Ovidiu Fira-Mlădinescu, Marc Monica and Voicu Tudorache), an eternal problem of differential diagnosis and
"Asthma with sensitization to ambrosia: diagnostic and therapeutic features" (Carmen Panaitescu), a topical subject due to the invasion of this ubiquitous plant in Romania as well. The last session also aroused the interest of the audience through an equally attractive offer. One by one was highlighted in this presentation group topics, such as "INSPIRO: Adherence to inhaler treatment - what have I learned?" (Ruxandra Ulmeanu) the experience of an RSP initiative on asthma education and COPD with the chronic patient suffering of such obstructive diseases, "Diagnostic problems in Churg-Strauss Syndrome" (Diana Deleanu) and "The role of the pneumologist in Churg-Strauss Syndrome" (Oana Deleanu) two mirror approaches of a more rare condition but with many diagnostic pitfalls, "The effect of air pollution on physical exercise" (Alina Croitoru) with multiple clinical and therapeutic connotations related to the environment and ending within the last two topics with a transfer of knowledge to the multidisciplinary allergist-pneumologist team "Asthmaanaphylaxis in children"(Camelia Berghea) and "Asthmaanaphylaxis connections in adults" (Corina Ureche).

This conference was a different experience to more than 300 participants who thus have had the opportunity to memorise and deepen problems generated by other hidden corners of asthma disease, not exposed in the classic monodisciplinary sessions of the two professional associations. The support of these topics was also provided through the GSK, Astra Zeneca, Novartis and Chiesi satellite symposiums which scored practical elements with therapeutic valences in the life of an asthmologist. The success of this conference encourages us to continue with this type of annual meeting at the border between the two specialities. 